\title{
¿Lecciones para el futuro? Cambios en los determinantes del empleo femenino en épocas de recesión en la ciudad de México, 1970-1976*
}

\author{
Jane R. Rubin-Kurtzman**
}

Entre 1970 y 1976, los determinantes individuales y familiares de la oferta de trabajo femenino y del empleo asalariado y no asalariado en la ciudad de México se vieron afectados por el deterioro de la economía y por las transformaciones demográficas que modificaron la composición individual y familiar de la fuerza de trabajo. Las mujeres casadas y las migrantes de origen urbano tenían mayores probabilidades de trabajar en 1976 que en 1970. A medida que se incrementaban las presiones para contribuir a la economía del hogar, las mujeres eran menos vulnerables que otros miembros del hogar a la participación como fuerza de trabajo. No obstante que los cambios en los determinantes del empleo asalariado entre 1970 y 1976 no resultaron significativos, los modestos cambios anticipados se dieron en la dirección esperada y fueron consistentes respecto de los observados en los años ochenta.

\section{Introducción}

En contraposición a las expectativas de que las mujeres sean atraídas al mercado de trabajo durante los periodos de prosperidad y expulsadas durante los de adversidad, en la ciudad de México se incrementó durante los años setenta la proporción de participación de las mujeres como fuerza de trabajo, a pesar de las condiciones de deterioro de la economía. Este artículo considera varias interpretaciones de esta paradoja. La primera, vinculada al modelo neoclásico de la movilidad del trabajo, atribuye el crecimiento continuo del empleo femenino en la ciudad de México, durante los años setenta, a las modificaciones estructurales de la demanda de trabajo asociada con el crecimiento económico de México, después de la Segunda Guerra Mundial. La segunda, argumenta que el agotamiento progresivo del modelo de desarrollo de sustitución

\footnotetext{
* Este artículo es parte de la tesis de doctorado de la autora sobre los cambios de las determinantes del empleo femenino de la ciudad de México durante los años setenta. La investigación fue financiada por las fundaciones Inter-American y el Population Council. También se recibió apoyo institucional por parte de El Colegio de México y UCLA. La autora agradece los certeros comentarios de Manuel García y Griego a la versión preliminar de este trabajo.Traducción de María Elena Muñoz Contreras.

** Rand.
} 
de importaciones, las vicisitudes económicas de los años setenta y las transformaciones demográficas de la sociedad mexicana afectaron al empleo femenino total y a la naturaleza del mismo. La tercera enfatiza la asociación entre la heterogeneidad ocupacional en México y el doble papel de las mujeres como productoras y reproductoras.

Esta investigación examina los cambios en la participación de la mujer en la fuerza de trabajo en la ciudad de México entre 1970 y 1976. El análisis se centra en dos aspectos del empleo femenino: la condición de actividad y la salarial. La condición de actividad es una variable dicotómica que clasifica a las mujeres según estén o no ocupadas. La condición salarial, también dicotómica, se refiere a la distribución en dos clases de las mujeres que trabajan: asalariadas y no asalariadas. Las trabajadoras no asalariadas se definen como independientes, por cuenta propia y familiares no remuneradas. La condición de actividad, que mide la proporción de mujeres ocupadas, ofrece un panorama de las tendencias del empleo total. La condición salarial destaca las características de las mujeres y de sus hogares, y estas particularidades controlan la naturaleza del trabajo que ellas realizan. Los datos se basan en una submuestra de 2520 mujeres de 20 a 49 años tomada de la Encuesta de Migración Interna, Estructura Ocupacional y Movilidad Social (fase A) y una submuestra comparable de 1592 mujeres tomada de la Encuesta Mexicana de Fecundidad de 1976 (que forma parte de la Encuesta Mundial de Fecundidad). 1

En este artículo se prueban diferentes hipótesis en relación con los cambios en los determinantes individuales y familiares de las condiciones de actividad y salarial. En otros artículos señalé que en 1970 las condiciones de actividad y salarial estaban determinadas por atributos individuales y familiares. La necesidad económica y la disponibilidad de atención para los dependientes del hogar determinaban el contexto para la participación de la fuerza de trabajo de los hogares y mediaban los efectos de los determinantes individuales del trabajo femenino, tales como el estado civil o el tamaño de la familia (Rubin-Kurtzman, 1991). En el presente artículo demuestro que, entre 1970 y 1976, los determinantes individuales y familiares de las condiciones de actividad y salarial se vieron afectados con el tiempo, debido a las

1 La Encuesta de Migración Interna, Estructura Ocupacional y Movilidad Social se llevó a cabo en el último trimestre de 1969 y el primero de 1970, y la Encuesta Mexicana de Fecundidad se levantó durante el último trimestre de 1976 y el primero de 1977. El hecho de que cada encuesta superponga dos años no invalida las condiciones económicas o demográficas descritas. 
transformaciones demográficas de México y al deterioro de la economía.

La investigación se centra en el periodo 1970-1976 por dos razones. Este marco temporal ofrece la primera oportunidad en la historia mexicana, desde 1940, para examinar las tendencias del empleo femenino durante un periodo de estancamiento económico, disminución de la inversión, inflación, desigualdad de ingresos, inestabilidad monetaria y creciente endeudamiento externo (Rendón y Salas, 1987; Tello, 1986). Los años setenta proporcionan también nueva luz sobre los cambios en la participación de la mujer como fuerza de trabajo durante los ochenta. Las tendencias del empleo de las mujeres en el mercado de trabajo urbano durante los años ochenta han sido consideradas como una respuesta a las deterioradas condiciones económicas por parte de las mujeres cuya participación como fuerza de trabajo se tornó indispensable para satisfacer las necesidades básicas de los hogares (García, 1989). La proporción de mujeres dentro de la fuerza de trabajo se incrementó, y el no asalariado progresó a expensas del asalariado. El empleo aumentó en mayor medida entre las mujeres de más edad, con menor escolaridad, casadas y con hijos (García y Oliveira, 1992). A pesar de que estos hallazgos han sido interpretados como una desviación de las tendencias anteriores, los datos de 1970-1976 ilustran el hecho, poco conocido, de que en los años setenta ya existían respuestas similares a las condiciones de deterioro económico.

Enfoques teóricos sobre el empleo femenino, el crecimiento económico y la recesión

Diversas perspectivas ofrecen explicaciones sobre la continua expansión de la participación de las mujeres de la ciudad de México dentro de la fuerza de trabajo durante la década de los setenta. Estos enfoques llaman la atención sobre la asociación entre el empleo femenino y el crecimiento económico, los obstáculos a la absorción del trabajo en el mercado laboral urbano y las opciones al empleo asalariado.

Al cuestionar la naturaleza de la estructura de los cambios en la demanda de trabajo, uno de los enfoques argumenta que si el empleo femenino en la ciudad de México se incrementó como resultado de las oportunidades de trabajo relacionadas con la industrialización de México en la posguerra y con la creciente disponibilidad de sustitutos en las labores domésticas, entonces los aumentos en el empleo deberían haberse retrasado en la medida 
en que el cuidado de los niños pequeños y el mantenimiento del hogar se volvieron relativamente más caros y que la recesión redujera la demanda de trabajo (Rubery, 1988; Humphries, 1988). Alternativamente, la relación entre el empleo femenino y el crecimiento económico en la ciudad de México puede ser contra-cíclica. Si eso fuese cierto, las mujeres serían contratadas con menores salarios en las ocupaciones anteriormente desempeñadas por los hombres a medida que los patrones adoptaran estrategias de ahorro de costos en respuesta a la recesión (Benería, 1983; Rubery, 1988). Paralelamente, la inestabilidad del trabajo masculino convertiría el hasta entonces "secundario" empleo femenino en la principal fuente de ingresos para el hogar. Una tercera perspectiva asegura que si los cambios estructurales en el sistema de producción incrementaron la demanda de trabajo femenino y los cambios permanentes en el sistema social y familiar sancionaron y avalaron el empleo de la mujer fuera del hogar, entonces la incorporación de las mujeres a la economía asalariada habría persistido y posiblemente se habría incrementado a pesar de la recesión económica. En estas condiciones, la expansión del empleo femenino podría ser resultado de uno de estos factores: mayor igualdad de géneros en el mercado de trabajo; persistencia de ocupaciones diferenciales por género, o la búsqueda de mano de obra barata en condiciones de recesión (Rubery, 1988).

Estas perspectivas daban cuenta inadecuada de los obstáculos estructurales a la absorción del trabajo, ${ }^{2}$ que impidieron la libre movilidad intersectorial e interregional del empleo y dieron por resultado la heterogeneidad de la estructura ocupacional en México (Jusidman, 1989). La heterogeneidad ocupacional, característica central del mercado de trabajo urbano, da contexto a las decisiones individuales y familiares, especialmente en lo que se refiere al trabajo femenino y a la migración laboral. El análisis de la heterogeneidad ocupacional también arroja luz sobre los diferenciales en las ocupaciones, el ingreso y los estándares de vida, y señala la manera en que las familias reproducen sus circunstancias de vida en condiciones de desigualdad social, bajos ingresos, inestabilidad laboral y continuo empobrecimiento (Arizpe, 1983).

${ }^{2}$ Los ejemplos de obstáculos estructurales a la absorción laboral incluyen: la orientación, intensiva en capital, de la industrialización mexicana, la falta de articulación interna entre el aparato productivo y la tecnología apropiada, y el exceso de oferta de trabajo sobre la demanda, como resultado del rápido crecimiento de la población y el flujo de trabajo migrante sin capacitación, de las áreas rurales a las urbanas (Souza y Tokman, 1975; Portes y Benton, 1984). 
La investigación sociológica sobre la asociación entre el empleo femenino y la heterogeneidad ocupacional ha destacado tres factores: las características del hogar que afectan la cantidad y el tipo de trabajo femenino necesario para la reproducción de la fuerza de trabajo, la división del trabajo en el hogar de acuerdo con el género, y la función económica del trabajo doméstico no remunerado (De Barbieri, 1978; Benería, 1979; Meillassoux, 1981; Alonso, 1982; García, Muñoz y Oliveira, 1982; Benería y Roldán, 1987). La participación de las mujeres en formas de producción alternativas está limitada por las condiciones del mercado laboral, la segregación por género de los empleos y la división sexual del trabajo. Las condiciones económicas adversas restringen la demanda de trabajo y la disponibilidad de empleos. La segregación en el empleo limita la movilidad ocupacional, especialmente en épocas de recesión, y permite que los patrones paguen sistemáticamente menores salarios a las mujeres (Milkman, 1976; Hartmann, 1976). La división del trabajo en el hogar obliga a las mujeres a dedicar la mayor parte de su tiempo al quehacer doméstico no remunerado. En respuesta a estas condiciones, las mujeres aceptan empleos remunerados con salarios menores o se involucran en actividades no asalariadas que les permiten generar un ingreso monetario, al mismo tiempo que cumplen con sus obligaciones domésticas.

\section{Hipótesis}

El punto de partida del razonamiento que se presenta más adelante es la expectativa de que para 1976 la proporción de participación de las mujeres en la fuerza de trabajo, y su distribución entre las categorías de trabajadoras se verían afectadas por el receso de la economía y por las transformaciones demográficas que modificaron la composición individual y familiar de la población femenina. La inmigración continua a la ciudad de México y el crecimiento relativo del tamaño de la cohorte de mujeres en edad activa alteraría la probabilidad de trabajar y la de ser a salariadas. Los cambios en la composición incrementarían la oferta de buscadoras de empleo, precisamente en una época de demanda de trabajo limitada. Al desarrollar el razonamiento de que el trabajo no asalariado se expandió en respuesta a las condiciones económicas deterioradas, se obtiene que la contracción de las oportunidades de trabajo asalariado en el mercado urbano contribuiría al aumento de la proporción de mujeres ocupadas no asalariadas. 


\section{El efecto del tamaño de la cohorte en el empleo femenino}

En 1976, los efectos de periodo y de cohorte habrían afectado negativamente el empleo femenino en comparación con 1970. De acuerdo con Easterlin (1976), la posición competitiva de los individuos en el mercado de trabajo dependería del tamaño relativo de la cohorte de las buscadoras de empleo a la cual él o ella pertenece. En México, el rápido crecimiento de la población durante las décadas de los cincuenta y sesenta, implicó en los años setenta la presencia de cohortes más grandes de mujeres en edad activa que pretendían ingresar al mercado de trabajo. El impacto de la alta fecundidad urbana sobre el tamaño de la cohorte se combinó con una fecundidad rural aún más grande, el continuo flujo de migrantes rurales a la capital, y ante éstos, la concentración desproporcionada de mujeres jóvenes en edad activa (Cabrera, 1970). A medida que el tamaño de la cohorte de mujeres en edad activa se expandió, la posición en el mercado de trabajo de las cohortes de mujeres nacidas en los años cincuenta y sesenta estaba en desventaja relativa frente a las nacidas antes.

Los efectos de cohorte y periodo chocaron en 1976, cuando las cohortes más jóvenes se encontraban buscando empleo en una época en la que las oportunidades disminuían. Por lo tanto, la proporción de mujeres menores a 35 años que estaban ocupadas habría disminuido entre 1970 y 1976, como resultado de las condiciones económicas desfavorables y de la desventaja relativa de las cohortes de mujeres más jóvenes en edad activa en el mercado de trabajo.

El efecto de la recesión sobre la relación entre el estado civil y el empleo femenino

La relación entre el estado civil y el empleo femenino estaría condicionada por las preferencias del patrón, por la necesidad de las mujeres de contribuir a la economía familiar y por la división del trabajo por géneros en el hogar. En 1970, cuando las condiciones económicas eran relativamente estables, la mayoría de las mujeres que constituían la fuerza de trabajo de la ciudad de México eran solteras o habían estado casadas. Las casadas tenían menos probabilidad de trabajar debido a sus responsabilidades domésticas y a que los patrones preferían contratar mujeres sin ese tipo de obligaciones (Rubin-Kurtzman, 1991).

Las preferencias de los patrones, las necesidades familiares y la división del trabajo en los hogares habrían cambiado al deterio- 
rarse las condiciones de la economía. La inestabilidad económica habría conducido a la disminución de la demanda de trabajo y al recorte de empleos. A pesar de las responsabilidades domésticas, las mujeres casadas se habrían sentido obligadas a trabajar a medida que la inflación aumentaba el costo de la canasta familiar y de que otros trabajadores del hogar, en especial los jefes de hogar masculinos, experimentaban despidos, incertidumbre en el empleo, o reducción del salario real en la forma de días de trabajo más cortos o de recortes salariales. Las consideraciones de costoeficiencia también habrían llevado a los patrones a contratar a mujeres casadas dispuestas a aceptar salarios menores y condiciones laborales menos favorables. ${ }^{3}$

El efecto de la recesión sobre la relación entre migración y empleo femenino

Diferentes enfoques analizan el efecto de la recesión sobre la composición nativo-migrante de la fuerza de trabajo femenina. Por una parte, la migración a la ciudad de México y la proporción de trabajadores migrantes se habrían incrementado a medida que la crisis en la agricultura intensificaba el éxodo rural. Mientras que la decisión de emigrar dependería de las limitaciones estructurales, como la estratificación de los empleos rurales por género y el desarrollo desigual de la economía rural (Arizpe, 1984), las redes urbano-rurales promoverían la migración selectiva de las personas que tuvieran mayor probabilidad de encontrar empleos en el mercado de trabajo urbano (Lomnitz, 1977), particularmente mujeres jóvenes, y solteras que buscaban trabajo como sirvientas.

Alternativamente, las noticias sobre los precios altos y la escasez de trabajo, habrían provocado en cierta medida, que se abatiera el flujo de nuevos migrantes a la ciudad de México. Al mismo tiempo, la demanda de trabajo femenino en México durante los años setenta no estaba concentrada necesariamente en las ciudades con economías más dinámicas (Oliveira, 1989). La escasez de empleos, la reducción en la emigración de las áreas rurales, la migración de retorno y los nuevos patrones de migración hacia las áreas con

3 Por ejemplo, Benería (1983) señala que en 1982, una época de mayor deterioro económico, los patrones en la ciudad de México preferían contratar a mujeres casadas porque su necesidad de contrarrestar la relativa vulnerabilidad económica de sus familias las hacía más dóciles, dispuestas a aceptar salarios más bajos y a no quejarse de condiciones de trabajo inadecuadas. 
perspectivas de empleo más prometedoras 4 habrían contribuido a la disminución en la proporción de participación de las migrantes femeninas en la fuerza de trabajo de la ciudad de México.

Las investigaciones antropológicas y sociológicas en Latinoamérica han refutado las expectativas teóricas según las cuales el trabajo es extraído de las áreas rurales en épocas de alta demanda y expulsado cuando el empleo urbano decae (Peattie, 1987; Batán, Browning y Jelin, 1973; Cornelius, 1975; Lomnitz, 1975). Portes y Walton (1981) encontraron que muchos migrantes permanecieron en las ciudades y finalmente fortalecieron su posición en la economía urbana. Si los futuros migrantes creyeron que su situación económica en la ciudad de México mejoraría con el tiempo, entonces la ciudad continuaría atrayéndolos en grandes cantidades y la proporción de migrantes integrados a la fuerza de trabajo se incrementaría, a pesar de la dificultad para asegurarse un empleo.

Por último, el efecto de la recesión económica sobre el empleo femenino variaría dependiendo del origen del migrante. Como el origen de la migración reflejaba las desigualdades regionales en el acceso a la educación, la proporción en la fuerza de trabajo de mujeres nativas de la ciudad de México, o de migrantes de otras ciudades, habría disminuido menos que la proporción que venía de las áreas rurales.

\section{El deterioro económico, el desempleo y el trabajo no asalariado}

Además de su efecto sobre el empleo femenino total, el deterioro de la economía habría tenido un impacto significativo sobre la distribución de las mujeres ocupadas entre las clases de asalariadas versus las no asalariadas. 5 Una forma de que las mujeres fueran capaces de superar la demanda restringida de trabajo, era la de ge-

4 El empleo en las maquiladoras en propiedad extranjera a lo largo de la frontera mexicana con Estados Unidos y la posibilidad de cruzar ilegalmente la frontera para trabajar en ese país, pudieron haber dirigido parte del flujo de la migración femenina fuera de la ciudad de México.

${ }^{5}$ El resurgimiento del sistema de subcontratación y la compatibilidad entre el trabajo industrial doméstico y el doméstico no remunerado en la ciudad de México han llamado la atención sobre la creciente complejidad de las formasi de producción en México (Alonso, 1982; Benería y Roldán, 1987). Teóricamente no es claro si deba clasificarse a los trabajadores domésticos industriales como asalariados o no asalariados; cualquier clasificación es convincente. Hay que admitir que la forma de clasificar el trabajo doméstico industrial influirá en los resultados. Los datos no proporcionan información sobre el trabajo doméstico industrial, como una categoría de trabajo distinta. 
nerar un ingreso por actividades no asalariadas. Entonces, a pesar de que un mayor número de mujeres se veían obligadas a trabajar, la escasez de empleos asalariados daría por resultado un aumento en la proporción de mujeres ocupadas no asalariadas. En otras palabras, en relación con 1970, la adversidad económica de 1976 tendría un efecto negativo sobre el trabajo asalariado y un efecto positivo sobre el no asalariado.

\section{El efecto de la escolaridad sobre el trabajo no asalariado}

Las respuestas ante la disminución de las oportunidades de empleo habrían variado de acuerdo con la escolaridad. Considerando la escolaridad como una aproximación de la clase social, principalmente las mujeres con mayor escolaridad debieran experimentar la adversidad económica, aunque no en forma exclusiva, en términos de una pérdida de trabajo asalariado; esto es, se incrementaría la proporción de mujeres con mayor escolaridad que no trabajaban. Mientras que el bajo estatus asociado generalmente al trabajo no asalariado (con la excepción de las profesionistas) haría menos atractiva esta opción para las mujeres con mayor nivel de escolaridad, las mujeres con escasa escolaridad habrían tenido mayor probabilidad de cambiar a las actividades no asalariadas. Aunque la amenaza de una disminución de sus estándares de vida llevaría a algunas mujeres de las clases media y alta a involucrarse en formas "elegantes" de trabajo no asalariado (artesanías, clases privadas, asesorías y otros tipos de servicios), los bienes y servicios que proporcionaban eran más superfluos y relativamente más caros que los bienes ofrecidos a través del comercio en pequeña escala, las mercancías hechas en casa y los servicios proporcionados por las mujeres pobres. Como la demanda de artículos de lujo y de servicios se reduciría en épocas difíciles, la ganancia relativa de las mujeres de las clases media y alta en las actividades no asalariadas sería pequeña comparada con la de las mujeres pobres. Como el esfuerzo excedía a la recompensa, las mujeres con mayor nivel de escolaridad se verían desalentadas a emprender actividades no asalariadas. El resultado final sería un incremento en la proporción de mujeres con mayor nivel de escolaridad que no trabajaban.

La participación de las migrantes en las formas de producción alternativas

A pesar de que la participación en las formas de producción alternativas constituyó el principal mecanismo a través del cual las 
migrantes sobrevivían en la economía urbana, la edad y la escolaridad afectarían su distribución entre las clases de trabajadoras asalariadas, versus las no asalariadas. Las migrantes rurales jóvenes, incapaces de encontrar trabajo como sirvientas asalariadas, tendrían mayor probabilidad de regresar a su hogar, mientras que las migrantes de más edad se involucrarían en actividades no asalariadas en la ciudad de México. De igual manera, las migrantes con mayor nivel de escolaridad serían capaces de encontrar trabajo asalariado o generar sus propias actividades no asalariadas.

Evidencia de los cambios en la condición de actividad: la proporción de mujeres incorporadas a la fuerza de trabajo

En 1970, las mujeres con más desventajas en la ciudad de México -las que habían estado casadas y tenían niños, las migrantes rurales pobres y las que vivían en hogares con jefe de familia femenino- también eran, probablemente, las que más trabajaban (RubinKurtzman, 1991). El estado civil, el tamaño de la familia y la condición migratoria eran los principales determinantes individuales de la condición de actividad. Las mujeres casadas eran, probablemente, las que menos trabajaban. Dentro del ámbito familiar, el género del jefe del hogar, la participación de otros miembros de la familia en la fuerza de trabajo, el número de dependientes en el hogar, y la presencia de sirvientas, constituían los determinantes significativos del empleo femenino. Las mujeres que vivían en hogares con jefe femenino tenían mayor probabilidad de trabajar que las que vivían en hogares encabezados por hombres. ${ }^{6} \mathrm{La}$ asociación positiva entre el número de trabajadores por hogar y el empleo femenino, denotaban el ingreso inadecuado del principal generador de ingresos, y en el caso de los hogares nucleares, a los que se encontraban en etapas relativamente más avanzadas del ciclo de vida.

Aunque en 1970 las mismas variables individuales y familiares determinaban tanto la condición de actividad como la salarial, la dirección de la asociación entre el empleo no asalariado y algunos predictores de variables independientes se revirtió. Las trabajadoras no asalariadas generalmente eran de más edad, migrantes

6 La jefatura del hogar fue definida por el entrevistado. Generalmente, las mujeres casadas definieron a sus esposos como jefes del hogar. Los instrumentos de la encuesta no estaban diseñados para captar los cambios en la definición que tomaran en cuenta los ingresos diferenciales, la condición de ocupación del marido o la presencia o ausencia del esposo en el hogar. 
casadas con familias grandes. El estado civil de casada era el predictor más fuerte del empleo no asalariado. Otros determinantes de la condición salarial incluían la edad, la escolaridad y la presencia de sirvientas y personas de más edad en el hogar (RubinKurtzman, 1993).

Entre 1970 y 1976, la proporción de mujeres integradas a la fuerza de trabajo disminuyó de 41 a $35.1 \%$ (véase el cuadro 1).7 Entre las mujeres trabajadoras, sólo la proporción de las no asalariadas se incrementó con el tiempo. A pesar de que la diferencia absoluta era pequeña, constituía un tercio del incremento respecto a $1970^{8}$ y era consistente en dirección y magnitud respecto de los patrones observados durante la década de los ochenta. ${ }^{9}$

\section{CUADRO 1}

Distribución porcentual de mujeres por condición ocupacional, ciudad de México, 1970-1976

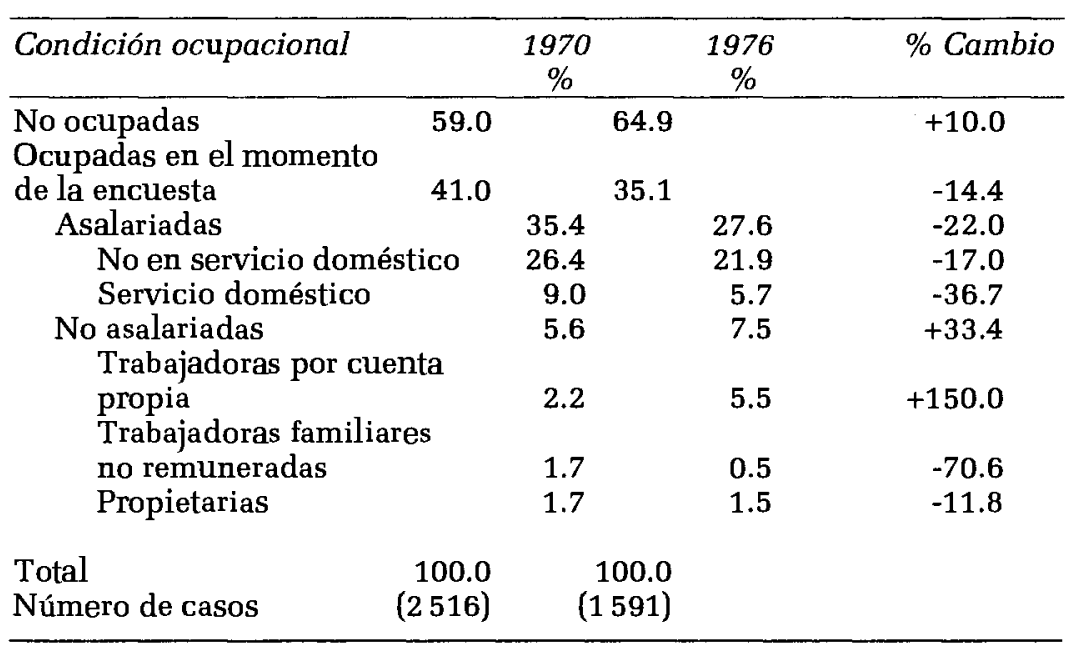

Nota: casos faltantes: menos de $1 \%$ en cualquier año.

7 La encuesta de 1976 no contiene información sobre la búsqueda de trabajo en ese momento. Sería de esperarse que más mujeres estuvieran buscando activamente trabajo en 1976 que en 1970.

8 Estos cambios están subestimados porque la Encuesta Mexicana de Fecundidad no fue diseñada para corroborar datos sobre empleo. Probablemente, la magnitud de un incremento en el trabajo no asalariado sería mayor con mejores datos.

${ }^{9}$ La proporción de mujeres trabajadoras por cuenta propia y trabajadoras familiares no remuneradas en la ciudad de México se incrementó en $46 \%$, de $14.7 \%$ de las trabajadoras a $21.5 \%$, entre 1984 y 1987 (Oliveira, 1989). 
En el cuadro 2 se presentan las relaciones bivariadas entre edad, estado civil y condición de actividad. Confirmando las expectativas de que el tamaño de la cohorte afectara adversamente la participación en la fuerza de trabajo de las cohortes más jóvenes en 1976, en relación con 1970, la proporción de mujeres jóvenes que trabajaban disminuyó en $18 \%$, al pasar de 44.2 a $36.1 \%$, comparada con una reducción de $6 \%$ en el empleo de las mujeres de más edad, es decir, de 35.3 a $33.2 \%$. El empleo femenino disminuyó más en las categorías de mujeres que tenían más posibilidades de trabajar en 1970, específicamente las solteras y las que habían estado casadas anteriormente. La participación de las mujeres solteras disminuyó de 75.5 a $66.9 \%$, mientras que el empleo de las anteriormente casadas cayó de 72.3 a $66.5 \%$. A poyando la hipótesis de que la necesidad económica debía obligar a más mujeres casadas a trabajar, la proporción de casadas incorporadas a la fuerza de trabajo se incrementó en $5.3 \%$; es decir, de 20.8 a 21.9 por ciento.

Al controlar la escolaridad, resultaron sorprendentes las diferencias en la participación en la fuerza de trabajo por condición

CUADRO 2

Ciudad de México: distribución porcentual de mujeres por condición ocupacional, edad, estado civil y condición migratoria, 1970-1976

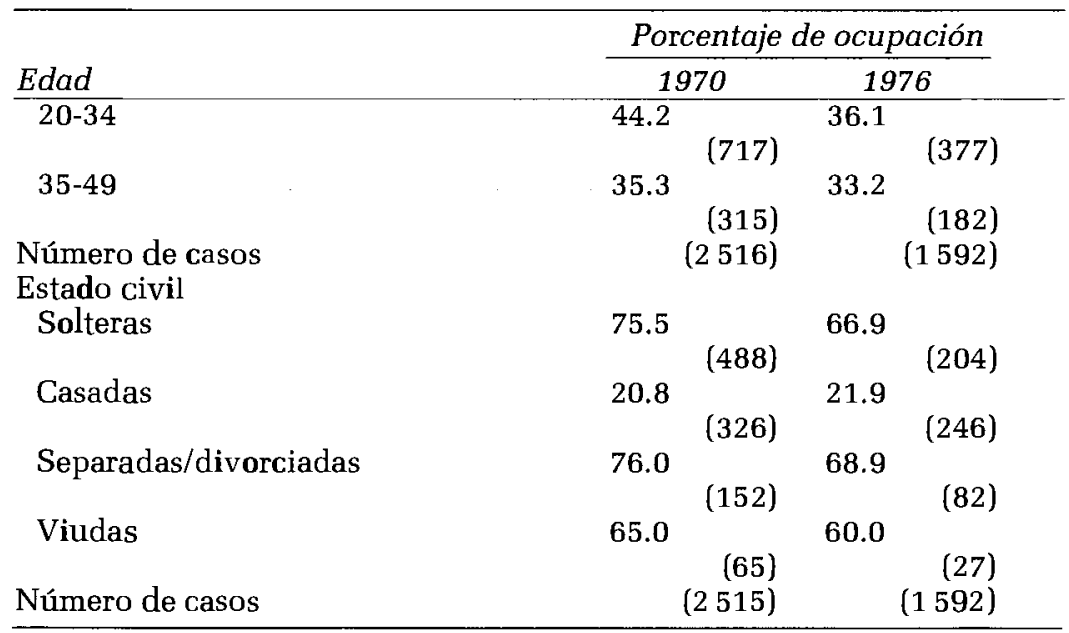

Notas: los números entre paréntesis son frecuencias. Casos faltantes: menos de $1 \%$ en cualquier año. 
migratoria (véase el cuadro 3). Como un testimonio de las desigualdades regionales de acceso a la educación, la disminución en la proporción de las migrantes rurales que trabajaban casi duplicó a la de las mujeres nativas. De manera más sorprendente, las migrantes de origen urbano surgieron como la única categoría de mujeres cuya participación en la fuerza de trabajo se incrementó con el tiempo, hallazgo sobre el que se volverá más adelante.

CUADRO 3

Proporción de mujeres en la fuerza de trabajo por condición migratoria y escolaridad, ciudad de México, 1970-1976

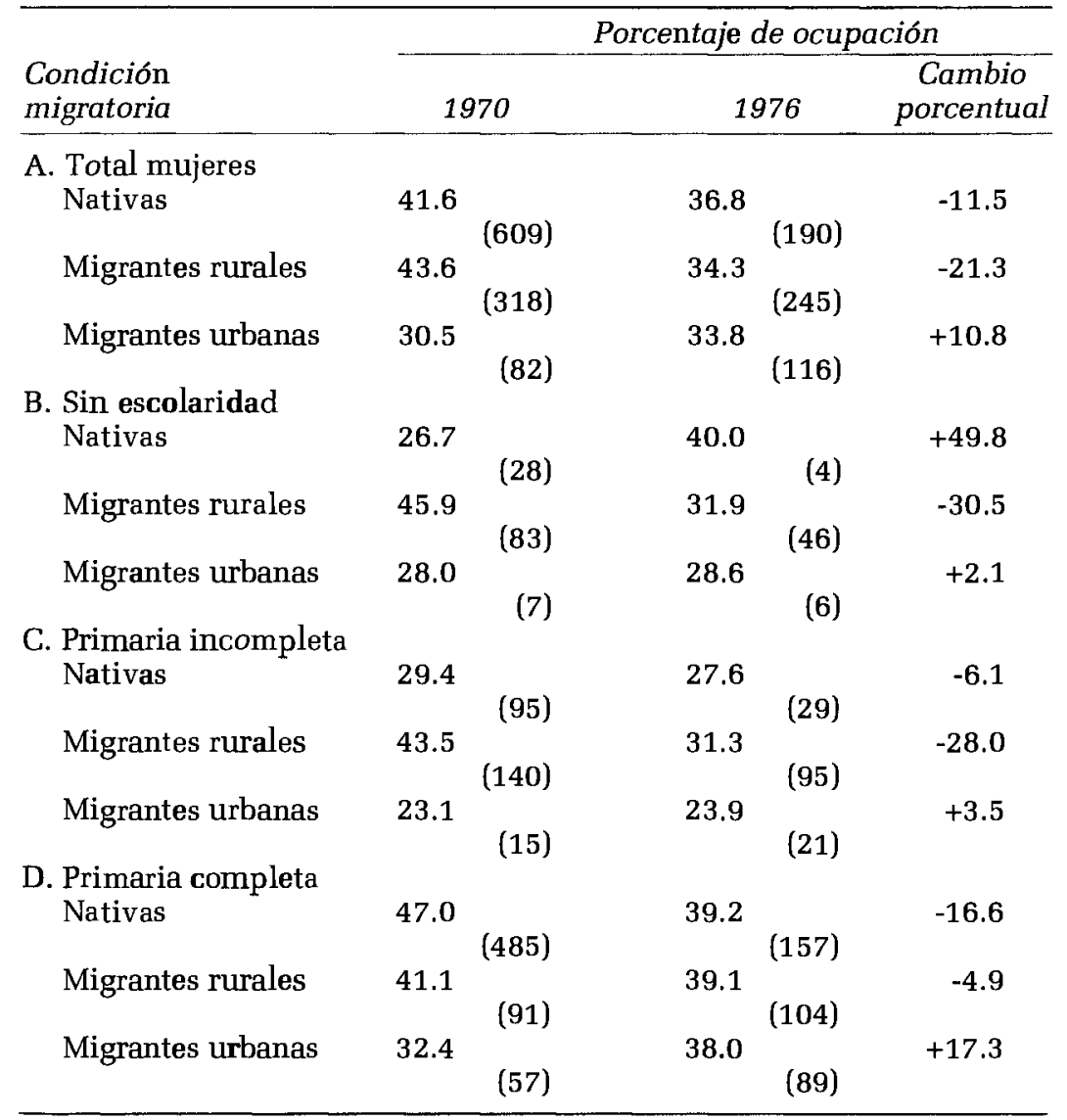

Notas: Casos faltantes: menos de $3 \%$ en cualquier año. Los números entre paréntesis son frecuencias. 
Evidencia de los cambios en la condición salarial: distribución de las mujeres ocupadas en clases de trabajadoras asalariadas versus no asalariadas

Al hacer un nuevo cálculo del cuadro 1, utilizando a las mujeres empleadas como el denominador, el cuadro 4 indica que el empleo asalariado en la ciudad de México disminuyó, mientras que el no asalariado se incrementó en $56 \%$, es decir, de 13.8 del total de mujeres que trabajaban en 1970, a 21.5 en 1976. El principal factor que explica la caída del empleo asalariado es la disminución de $26.7 \%$ en la proporción de mujeres empleadas como sirvientas. El empleo no asalariado casi se triplicó entre las que trabajaban de manera independiente, por cuenta propia y sin empleados; la categoría de trabajadoras más empobrecida en 1970. A pesar de que el número de trabajadoras familiares no remuneradas era relativamente pequeño, la proporción de mujeres ocupadas en esta categoría aumentó en dos tercios.

CUADRO 4

Distribución de mujeres ocupadas por clase de trabajadoras, ciudad de México, 1970-1976

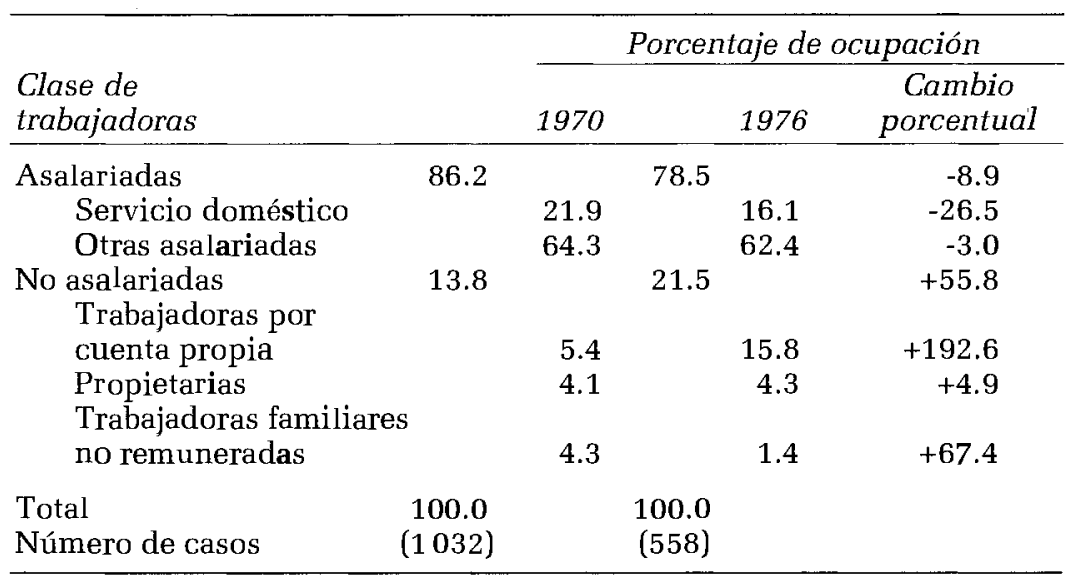

Nota: Casos faltantes: menos de $1 \%$ en cualquier año.

El cuadro 5 nos brinda la prueba de que la recesión económica no puso un alto a la migración hacia la ciudad de México. La proporción de mujeres nativas de la ciudad de México ${ }^{\mathrm{I0}}$ disminu-

10 Las nativas de la ciudad de México se definieron como las mujeres nacidas y con residencia continua en la ciudad de México o mujeres nacidas en cualquier 
yó de $59 \%$ de todas las mujeres encuestadas en 1970 , a $33 \%$ en 1976.11 A medida que la migración en familia a la capital pasó a ser de importancia creciente (García, Muñoz y Oliveira, 1979), la migración rural creció de 30 a $45 \%$ y la migración de las áreas urbanas se duplicó entre 1970 y 1976, de 11 a 22 por ciento.

CUADRO 5

Distribución porcentual de mujeres por condición migratoria, ciudad de México, 1970-1976 ( $N=4112)$

\begin{tabular}{lrr}
\hline Condición migratoria & 1970 & 1976 \\
\hline Nativas & 59.4 & 32.8 \\
Migrantes de origen rural & 29.6 & 45.4 \\
Migrantes de origen urbano & 10.9 & 21.8 \\
Total & 99.9 & 100.0 \\
Número de casos & $(2455)$ & $(1573)$ \\
\hline
\end{tabular}

Nota: Casos faltantes: menos de $3 \%$ en cualquier año.

Aunque Portes y Walton (1981) habían asegurado que el empleo no asalariado era el principal vehículo para la supervivencia del migrante en las ciudades del Tercer Mundo, en el cuadro 6 se presenta una situación más compleja en la ciudad de México, caracterizada por diferencias entre los migrantes rurales y urbanos y por paralelismos entre las mujeres nativas y las migrantes urbanas. La proporción de las migrantes rurales asalariadas disminuyó menos que la de las nativas o la de las migrantes de origen urbano. Una explicación podría ser que el empleo no asalariado requiere atributos empresariales o de escolaridad que no poseen las migrantes rurales no capacitadas. En 1970, las trabajadoras no asalariadas tenían mayor capacitación que las sirvientas, la mayoría de las cuales eran migrantes rurales, y tenían menor capacitación que las trabajadoras asalariadas, la mayoría de las cuales eran nativas. No existe ninguna razón para sospechar que esta re-

otra localidad, que llegaron antes de los 13 años y permanecieron en la ciudad de México. Las migrantes se definieron como las mujeres nacidas en cualquier otra localidad, que llegaron y permanecieron en la ciudad de México después de los 12 años y(o) las mujeres nacidas en la ciudad de México que salieron de ella siendo niñas y regresaron después de los 12 años. Las migrantes rurales se definieron como mujeres nacidas en áreas de menos de 20000 habitantes. Las migrantes urbanas se definieron como las mujeres nacidas en áreas de 20000 o más habitantes.

11 Las diferencias de las encuestas en la medición de la población migrante podrían haber inflado la proporción de migrantes en 1976, en relación con 1970. No obstante, aunque la magnitud del cambio pueda debatirse, su dirección no. Para mayor información sobre el tema, véase Rubin-Kurtzman, 1991b. 
lación haya cambiado con el tiempo. Otra explicación podría ser que las migrantes rurales recién llegadas tenían desventajas debido a que carecían de las redes necesarias para el empleo no asalariado.

En los cuadros 6 y 7 también se demuestra que la distribución de las migrantes ocupadas por condición salarial varían de acuerdo con la edad y el nivel de escolaridad. Entre las mujeres de mayor edad, la proporción de migrantes urbanas no asalariadas aumentó en 13 por ciento. El empleo no asalariado entre otras mujeres declinó. Las migrantes urbanas con un nivel de escolaridad relativamente mayor, tenían más capacidad para superar las condiciones adversas del mercado de trabajo.

\section{CUADRO 6}

Distribución porcentual de mujeres ocupadas por clases de trabajadoras, condición migratoria y edad, ciudad de México, 1970-1976 ( $\mathrm{N}=1560)$

\begin{tabular}{|c|c|c|c|c|c|}
\hline \multirow[b]{2}{*}{ Condición migratoria } & \multicolumn{5}{|c|}{ Porcentaje de asalariadas } \\
\hline & \multicolumn{2}{|c|}{1970} & \multicolumn{2}{|c|}{1976} & $\begin{array}{c}\text { Cambio } \\
\text { porcentual }\end{array}$ \\
\hline \multicolumn{6}{|l|}{ A. Total de mujeres } \\
\hline Nativas & 88.3 & (538) & 81.1 & (154) & -8.2 \\
\hline Migrantes rurales & 83.6 & (266) & 78.4 & (192) & -6.2 \\
\hline Migrantes urbanas & 81.7 & (67) & 74.1 & (86) & -9.3 \\
\hline B. Mujeres de 20 a 34 años & & & & & \\
\hline Nativas & 92.1 & $(430)$ & 89.9 & (124) & -2.4 \\
\hline Migrantes rurales & 89.7 & (166) & 87.7 & (135) & -2.2 \\
\hline Migrantes urbanas & 96.1 & (49) & 77.8 & (63) & -19.0 \\
\hline C. Mujeres de 35 a 49 años & & & & & \\
\hline Nativas & 76.1 & (108) & 57.7 & (30) & -24.2 \\
\hline Migrantes rurales & 75.2 & $(100)$ & 62.6 & (57) & -16.8 \\
\hline Migrantes urbanas & 58.1 & (18) & 65.7 & (23) & +13.1 \\
\hline
\end{tabular}

Nota: Casos faltantes: menos de $2 \%$ en cualquier año. 
CUADRO 7

Distribución porcentual de trabajadoras asalariadas por escolaridad, ciudad de México, 1970-1976

\begin{tabular}{|c|c|c|c|c|c|}
\hline \multirow[b]{2}{*}{ Escolaridad } & \multicolumn{5}{|c|}{ Condición salarial } \\
\hline & $\begin{array}{l}\text { No ocu } \\
\text { padas } \\
\%\end{array}$ & $\begin{array}{c}\text { Trabaja- } \\
\text { - doras asa- } \\
\text { lariadas } \\
\%\end{array}$ & $\begin{array}{c}\text { Trabaja- } \\
\text { doras no } \\
\text { asalaria- } \\
\text { das } \%\end{array}$ & $\begin{array}{c}\text { Total } \\
\%\end{array}$ & $N$ \\
\hline \multicolumn{6}{|l|}{ Sin estudios } \\
\hline 1970 & 62.3 & 32.7 & 5.0 & 100.0 & $(321)$ \\
\hline 1976 & 66.5 & 21.9 & 11.7 & 100.1 & $(179)$ \\
\hline Cambio porcentual 76-70 & +6.7 & -33.0 & +134.0 & & \\
\hline \multicolumn{6}{|l|}{ Primaria incompleta } \\
\hline 1970 & 64.9 & 27.2 & 7.9 & 100.0 & (718) \\
\hline 1976 & 71.0 & 18.7 & 10.3 & 100.0 & $(503)$ \\
\hline Cambio porcentual 76-70 & +9.4 & -31.2 & +30.4 & & \\
\hline \multicolumn{6}{|l|}{ Primaria o más } \\
\hline 1970 & 55.5 & 39.9 & 4.6 & 100.0 & $(1459)$ \\
\hline 1976 & 61.2 & 33.5 & 5.3 & 100.0 & (910) \\
\hline Cambio porcentual 76-70 & +10.3 & -16.0 & +15.2 & & \\
\hline
\end{tabular}

Nota: Casos faltantes: menos de $1 \%$ en cualquier año.

Análisis multivariado de los cambios en los determinantes de la participación femenina en la fuerza de trabajo

Como sugiere el planteamiento anterior, las modificaciones del empleo femenino se habrían visto afectadas con el tiempo por los cambios en la propensión de las mujeres a trabajar o a ser asalariadas, y por las variaciones en la composición de las mujeres entre los predictores de las categorías. Utilizando la regresión logística, examiné la solidez de los modelos de 1970, para determinar la fuerza de trabajo y el empleo asalariado en el tiempo, y para delimitar los cambios atribuidos a la propensión de las mujeres a trabajar o a ser asalariadas, y los debidos a los cambios en la composición de la población femenina.

Los determinantes de la oferta de trabajo femenino debieran diferir muy poco entre 1970 y 1976. Es decir, restringiendo el análisis de 1976 a las mismas variables consideradas en 1970, el modelo de mejor ajuste para determinar el empleo en 1970 también debiera ser válido para 1976. Los cambios relativos en la composición, medidos con la distribución de los casos a través de las categorías de las variables independientes y con la propensión a trabajar, debieran explicar la disminución observada en la proporción de mujeres ocupadas en 1976. 
Para comprobarlo, combiné las muestras de 1970 y 1976, creando así una variable categórica independiente llamada AÑO, codifiqué $0=1970$ y $1=1976$, y estimé una ecuación que incorporó la interacción entre el año y cada una de las relaciones observadas en 1970. Los términos de interacción AÑO me permitieron evaluar si los coeficientes de 1976 diferían significativamente respecto a los de 1970. El coeficiente para la interacción entre AÑO y cualquier valor dado era la magnitud del cambio con el tiempo en la propensión a trabajar de las mujeres con esa característica, y el valor $p$ era la significancia de ese cambio, respecto de un modelo que suponía la constancia de la propensión a trabajar.12 Enseguida, especifiqué modelos alternativos de determinación del empleo para el periodo 1970-1976. El modelo 1 postuló que no debiera haber cambios en los coeficientes entre 1970 y 1976; sólo contenía las variables individuales y familiares del modelo de mejor ajuste para 1970 .

El modelo 1 se expresó como:

$\operatorname{Ln}[P /(1-P)]=a+\sum b_{i}\left(I_{i}\right)+\sum b_{h}\left(H_{h}\right)$

en donde $[P /(1-P)]$ era la razón denominada "momio" del trabajo; el conjunto de los determinantes individuales del empleo asalariado se representaba como $I$, el de las variables familiares como $H$.

El modelo 2 tenía como hipótesis que los coeficientes de al menos algunas variables individuales y familiares, debían variar con el tiempo. El modelo 2 contenía el efecto principal de las variables, el término AÑO, y las interacciones de AÑO con todas las variables previamente especificadas a nivel individual y familiar.

El modelo 2 se expresó como:

$$
\operatorname{Ln}[P /(1-P)]=a+\sum b_{i}\left(I_{i}\right)+\sum b_{h}\left(H_{h}\right)+b_{k}(Y)+\sum b_{i k}(I Y)+\sum b_{h k}(H Y)
$$

en donde el conjunto de los determinantes individuales del empleo femenino se representaba como $I$, el conjunto de las variables familiares, como $H$, el término AÑO como $Y$, y las interacciones de AÑ como $I Y$ e $I H$.

En el cuadro 8 se evalúa la bondad de ajuste relativa de estos modelos, al probar la importancia de la diferencia en el modelo chi

12 Calculé el coeficiente para 1976, de la combinación de datos, restando el cambio del coeficiente en el tiempo al coeficiente de 1970. 
cuadrada. El cambio en el $G^{2}$ se refería a las diferencias en los coeficientes; es decir, la propensión de las mujeres a trabajar en cada categoría de variable. Al comparar el cambio en el $G^{2}$ y el cambio correspondiente en los grados de libertad del modelo que especificaba que no debía haber cambio en los "momios" log del empleo entre 1970 y 1976 (modelo 1) con el modelo en el que se anticipaba que ocurrirían algunas diferencias en los coeficientes (modelo 2), el cuadro 8 indica que la suma del término año, y al menos algunas de las interacciones de AÑ , aumentaba significativamente el poder explicativo del modelo de $1976\left(X^{2}\right.$ al 0.95 con 18 grados de libertad $=28.87<33.65$ ). Por lo tanto, sí cambió la propensión de las mujeres al trabajo en los predictores de algunas categorías.

A pesar de que el modelo mejoró estadísticamente, la mejoría, o el incremento en la $G^{2}$ entre el modelo 1 y el 2, fue pequeña. Sospeché entonces que sólo una o dos variables eran responsables del incremento total en la $G^{2}$ y que la mayoría de las interacciones con AÑO no eran significativas. En realidad, cuando examiné las interacciones del ANO para el modelo 2 término por término, sólo los coeficientes del estado civil y del número de trabajadores adicionales por hogar cambiaron significativamente. Eliminando todos los términos de las interacciones del AÑO no significativas (modelo 3), la diferencia en las $G^{2}$ entre los modelos 2 y 3 no resultó significativa ( $X^{2}$ al 95 con 15 grados de libertad $=25>17.19$ ). Por lo tanto, el modelo de mejor ajuste de la determinación del empleo femenino en 1976 fue casi el mismo que el de mejor ajuste en 1970, con excepción de los cambios en los efectos del estado civil de casada y del número de trabajadores adicionales en el hogar.

CUADRO 8

Razones estadísticas logarítmicas de máxima verosimilitud para modelos alternativos de cambios en los determinantes individuales y familiares del empleo femenino, ciudad de México, 1970-1976

\begin{tabular}{|c|c|c|c|}
\hline Modelo & Variables & Modelo $G^{2}$ & Modelo $D F$ \\
\hline 1 & $(I, H)$ & 1296.33 & 17 \\
\hline 2 & $\left(I, H, Y, I^{*} Y, H^{*} Y\right)$ & 1328.98 & 35 \\
\hline 3 & $\left(I, H, Y, Y^{*} M S, Y^{*} W\right)$ & 1311.79 & 20 \\
\hline Delta Modelo & 2-Modelo 1 & 33.65 & 18 \\
\hline Delta Modelo & 3-Modelo 2 & 17.19 & 15 \\
\hline
\end{tabular}

En el cuadro 9 se presenta la probabilidad del empleo femenino basada en los cambios observados en la proporción de mujeres que trabajaban. A pesar de que las mujeres casadas seguían siendo las que tenían menos posibilidad de trabajar que otras, mante- 
niendo todo lo demás constante, las mujeres casadas tenían significativamente más posibilidades de trabajar en 1976 que en 1970.13 Específicamente, el coeficiente para el estado civil aumentó de -1.99 a -1.46. Los hallazgos apoyan el argumento de que el ingreso de las mujeres casadas era esencial para la economía del hogar en 1976, y la oposición de los patrones a contratar mujeres casadas se vio atenuada por la perspectiva de pagar un salario menor a las trabajadoras casadas necesitadas.

\section{CUADRO 9}

Probabilidad de empleo femenino con base en los cambios observados en la propensión a trabajar de las mujeres, ciudad de México, 1970-1976 ( $\mathrm{N}=4$ 092)

\begin{tabular}{|c|c|c|c|c|c|}
\hline $\begin{array}{l}\text { Variable } \\
\text { (1) }\end{array}$ & $\begin{array}{c}\text { Beta de } \\
1970 \\
(2)\end{array}$ & $\begin{array}{c}\text { Cambios } \\
\text { en Beta } \\
1970-1976 \\
\text { (3) }\end{array}$ & $\begin{array}{c}\text { Beta de } \\
1976 \\
(4)\end{array}$ & $\begin{array}{c}\text { Media } \\
1970 \\
(5)\end{array}$ & $\begin{array}{c}\text { Media } \\
1976 \\
(6)\end{array}$ \\
\hline Intercepción & 1.8433 & 0.0864 & 1.9297 & 1 & 1 \\
\hline Escolaridad & 0.0244 & 0 & 0.0244 & 5.7109 & 5.5381 \\
\hline Edad & 0.0004 & 0 & 0.0004 & 31.4575 & 31.4499 \\
\hline Casada & -1.9924 & -0.5321 & -1.4603 & 0.6236 & 0.7056 \\
\hline Migrante rural & 0.4952 & 0 & 0.4952 & 0.3112 & 0.4473 \\
\hline Migrante urbana & -0.0528 & $\mathbf{0}$ & -0.0528 & 0.1069 & 0.2164 \\
\hline 1 hijo & -0.0261 & 0 & -0.0261 & 0.1164 & 0.1383 \\
\hline 2 a 5 hijos & -0.4005 & 0 & -0.4005 & 0.3728 & 0.4346 \\
\hline 6 o más hijos & -0.5084 & 0 & -0.5084 & 0.2098 & 0.2075 \\
\hline Hogar ampliado & -0.0495 & 0 & -0.0495 & 0.3716 & 0.3103 \\
\hline Otros hogares & 0.2231 & 0 & 0.2231 & 0.0076 & 0.0140 \\
\hline \multicolumn{6}{|l|}{ Trabajadores } \\
\hline adicionales & 0.1196 & 0.1277 & -0.0081 & 2.5767 & 2.2113 \\
\hline $\begin{array}{l}1 \text { a } 2 \text { trabajadores } \\
\text { adicionales }\end{array}$ & -1.1838 & 0 & -1.1831 & 0.3923 & 0.3718 \\
\hline $\begin{array}{l}3 \text { o más trabajadores } \\
\text { adicionales }\end{array}$ & -0.7218 & 0 & -0.7218 & 0.4857 & 0.5171 \\
\hline Género del jefe & -0.8113 & 0 & -0.8113 & 0.8478 & 0.8579 \\
\hline Jóvenes & -0.0378 & 0 & -0.0378 & 0.5676 & 0.6929 \\
\hline Viejos & 0.1812 & 0 & 0.1812 & 0.1324 & 0.0539 \\
\hline Sirvientas & 0.6016 & 0 & 0.6016 & 0.1725 & 0.1034 \\
\hline
\end{tabular}

13 Para determinar el cambio en el efecto del estado civil, derivé el coeficiente del estado civil para 1976 restando la interacción del término AO para el estado civil del coeficiente de 1970 [ (-1.992) - (-0.532 = -1.46) ]. El log de los "momios": se convirtieron en "momios" al tomar el antilogaritmo. 
CUADRO 9 (continuación)

\begin{tabular}{|c|c|c|c|}
\hline \multirow[b]{2}{*}{$\begin{array}{l}\text { Variable } \\
\text { (7) }\end{array}$} & \multicolumn{3}{|c|}{ Contribución a los cambios del logito } \\
\hline & $\begin{array}{c}\text { Contribución } \\
\text { al logito } \\
\left(70 b^{\star} 70 \mathrm{~m}\right) \\
(8)\end{array}$ & $\begin{array}{c}\text { Propensión } \\
\left(76 b^{\star} 70 m\right) \\
(9)\end{array}$ & $\begin{array}{c}\text { Propensión y } \\
\text { composición } \\
\left(76 b^{\star} 76 m\right) \\
(10)\end{array}$ \\
\hline Intercepción & 1.8433 & 1.9297 & 1.9297 \\
\hline Escolaridad & 0.1420 & 0.1420 & 0.1351 \\
\hline Edad & 0.0126 & 0.1026 & 0.0126 \\
\hline Casada & -1.2425 & -0.9106 & -1.0304 \\
\hline Migrante rural & 0.1541 & 0.1541 & -0.2215 \\
\hline Migrante urbana & -0.0056 & -0.0056 & -0.0114 \\
\hline 1 hijo & -0.0030 & -0.0030 & -0.0036 \\
\hline 2 a 5 hijos & -0.1493 & -0.1493 & -0.1741 \\
\hline 6 o más hijos & -0.1067 & -0.1067 & -0.1055 \\
\hline Hogar ampliado & -0.1084 & 0.0184 & 0.0154 \\
\hline Otros hogares & 0.0017 & 0.0017 & 0.0031 \\
\hline $\begin{array}{c}\text { Trabajadores } \\
\text { adicionales }\end{array}$ & 0.3082 & -0.0209 & -0.0179 \\
\hline 1 a 2 trabajadores & & & \\
\hline $\begin{array}{l}\text { adicionales } \\
3 \text { o más trabajadores }\end{array}$ & -0.4644 & -0.4644 & 0.4401 \\
\hline $\begin{array}{l}\text { adicionales } \\
\text { Género del jefe de }\end{array}$ & -0.3506 & -0.3506 & -0.3732 \\
\hline hogar & -0.6878 & -0.6878 & -0.6960 \\
\hline Jóvenes & -0.0215 & 0.0215 & -0.0262 \\
\hline Viejos & 0.0240 & 0.0240 & 0.0098 \\
\hline Sirvientas & 0.1038 & 0.1038 & 0.0622 \\
\hline Conteo del logito & -0.4601 & -0.3710 & -0.5198 \\
\hline $\begin{array}{l}\text { Probabilidad de } \\
\text { trabajo }\end{array}$ & 0.3870 & 0.4083 & 0.3729 \\
\hline
\end{tabular}

Aunque la presencia de otros trabajadores en el hogar mejoraba las oportunidades de trabajo de la mujer en 1970, esto ya no fue válido en 1976. El coeficiente disminuyó de 0.12 en 1970 a -0.03, casi cero, en 1976.14 Independientemente del año, los hogares con múltiples trabajadores eran sobre todo aquellos en los que el ingreso inadecuado del jefe del hogar obligaba a trabajar a otros

14 Aunque el cambio del coeficiente para los trabajadores adicionales era significativo en 1970-1976, probablemente sea cierto que el coeficiente para los trabajadores adicionales por hogar no fuera significativo en 1976. Es decir, el cambio en el coeficiente $(-0.15)$ fue significativo porque pasó de un valor significativo en 1970 $(-0.12)$ a un valor no significativo en $1976(-0.03)$. 
miembros del hogar. Probablemente, los hogares con múltiples trabajadores estaban también en etapas avanzadas del ciclo de vida en las que era menos posible que las mujeres tuvieran grandes responsabilidades en el cuidado de los hijos. Para 1976, el empleo femenino estaba más limitado por las condiciones del mercado de trabajo y por la reducida demanda de trabajo, que por la posible contribución monetaria de otros trabajadores del hogar.

Los efectos de los cambios en el estado civil y en el número de trabajadores adicionales sobre el valor del logito y sobre la probabilidad de empleo, interactuaron negativamente debido a que los coeficientes eran más o menos de la misma magnitud con signos en direcciones opuestas. Al mantener constante la composición en los niveles de 1970, la probabilidad total de empleo aumentó ligeramente, de 39\% en 1970 a $41 \%$ en 1976 (columnas 8 y 9 del cuadro 9). 15

Cuando consideré el efecto de cada cambio por separado en la propensión, surgieron diferencias más sustanciales. Al mantener constantes todos los otros cambios en la propensión y composición en los niveles de 1970, el hecho de que las mujeres casadas tuvieran más probabilidades de trabajar en 1976 aumentó la probabilidad total de trabajo en $8 \%$, al pasar de $39 \%$ en 1970 a $47 \%$ en 1976. De la misma manera, al evaluar el efecto de los trabajadores familiares con la media de 1970, la probabilidad de empleo disminuyó en $8 \%$, pasando de $39 \%$ en 1970 a $31 \%$ en 1976.

En la columna 10 del cuadro 9 se evalúan los cambios en la composición y los efectos combinados de las diferencias de la propensión en el estado civil, los trabajadores adicionales por hogar y los factores no definidos considerados en el cambio del intercepto sobre la probabilidad pronosticada de trabajo. Esta combinación de factores contribuye a una ligera disminución en la probabilidad total estimada de trabajo, de 39 a 37 por ciento.

En el cuadro 10 se analizan por separado los efectos combinados de los cambios en la propensión y composición para las variables cuya media cambió en $5 \%$ entre 1970 y 1976: el estado civil de casada, la condición migratoria, la proporción con 2-5 hijos, la proporción con hijos pequeños en el hogar y la proporción con sirvientas. Para determinar cuál habría sido el cambio de la probabilidad pronosticada de trabajo en 1970 (0.39), si la propensión a trabajar y la composición de mujeres en cada variable

15 A pesar de que en el presente caso seleccioné las medias de 1970 como estándar, habría resultado igualmente aceptable utilizar las de 1976 o las del conjunto mezclado de datos (1970-1976) (véase Rubin-Kurtzman, 1991). 
hubieran sido las de 1976, sustituí uno por uno los valores del coeficiente de 1976 y la media para cada variable. A pesar de que las diferencias para la mayoría de las variables fue pequeña, la probabilidad total de trabajo habría sido $5 \%$ más alta si la composición y la propensión a trabajar de las mujeres casadas hubiera permanecido igual.

CUADRO 10

Cambios en la probabilidad de trabajo para variables seleccionadas, ciudad de México, 1976

\begin{tabular}{lccc}
\hline & \multicolumn{3}{c}{ Probabilidad de trabajo } \\
\cline { 2 - 4 } Variable & Media, 1970 & Media, 1976 & 1976b, 1976m \\
\hline Estado civil & .624 & .706 & .438 \\
Migrante rural & .311 & .447 & .403 \\
Migrante urbana & .107 & .216 & .386 \\
2 a 5 hijos & .373 & .435 & .381 \\
Hogar extendido & .372 & .310 & .388 \\
Niños pequeños & .568 & .693 & .385 \\
Sirvientas & .172 & .103 & .377 \\
\hline
\end{tabular}

No hubo cambio en el tiempo de la propensión a trabajar de las mujeres jóvenes con mayor nivel de escolaridad y solteras. Por el contrario, los hallazgos sugieren que la recesión redujo la demanda de trabajo calificado y alteró las preferencias de los patrones, de tal forma que se mejoraron las perspectivas de empleo de las mujeres casadas de más edad. Los hogares individuales resintieron la crisis principalmente en términos de la inflación y de los recortes salariales. Los subsidios a la salud, la vivienda, los alimentos, y otros programas de bienestar social de la administración del presidente Echeverría, ejercieron un efecto amortiguador de la recesión económica al mejorar las posibilidades de supervivencia de algunos sectores de la sociedad, al tiempo que aceleraron la inflación que pretendían combatir.

Análisis multivariados de los cambios en los determinantes del empleo asalariado

Al restringir el análisis de 1976 a las variables consideradas en 1970 , pensé que algunos cambios en la composición y en la propensión de las trabajadoras a ser asalariadas explicarían la disminución observada en la proporción de las trabajadoras asalaria- 
das. Utilizando el subconjunto de mujeres que estaban trabajando en ese momento de la combinación de datos 1970-1976, comparé la determinación de los modelos del empleo asalariado para 1970 y 1976 (véase el cuadro 11). Suponiendo que no debía haber cambio en los coeficientes en el tiempo, el modelo 1 contenía sólo las variables individuales y familiares en el modelo de mejor ajuste para 1970. El modelo 1 se expresaba como:

$$
\operatorname{Ln}[P /(1-P)]=\mathrm{a}+\sum b_{i}\left(I_{i}\right)+\sum b_{h}\left(H_{h}\right)
$$

en donde $[P /(1-P)]$ representaba la razón de los "momios" del empleo asalariado; el conjunto de los determinantes individuales del empleo asalariado se representaba como $I$, y el conjunto de variables familiares como $H$.

CUADRO 11

Razones estadísticas logarítmicas de máxima verosimilitud y bondad de ajuste de los modelos de determinación de empleo asalariado, ciudad de México, 1970-1976

\begin{tabular}{lcc}
\hline Modelo & Modelo $G^{2}$ & Modelo DF \\
\hline Modelo 1: $(I, H)$ & 317.90 & 19 \\
Modelo 2: $\left(I, H, Y, I^{*} Y, H^{*} Y\right)$ & 340.38 & 37 \\
Delta Modelo 2-Modelo 1 & 22.48 & 18 \\
\hline
\end{tabular}

El modelo 2 incluía los efectos principales; el término AÑO y las interacciones de AÑO con todas las variables especificadas:

$\operatorname{Ln}[P /(1-P)]=a+\sum b_{i}\left(I_{i}\right)+\sum b_{h}\left(H_{h}\right)+b_{k}(Y)+\sum b_{i k}(I Y)+\sum b_{h k}(H Y)(4]$

Los coeficientes para los términos de las interacciones de AÑO representaban la magnitud del cambio en la propensión de las trabajadoras con la característica de ser asalariadas; el valor $p$ representaba la significancia de ese cambio en relación con el modelo que suponía que no había cambio.

Aunque esperaba que los coeficientes de escolaridad y del estatus marital de casada cambiarían, el hecho de añadir los términos de interacción de AÑO a los datos combinados de 1970-1976 no mejoró significativamente el modelo. Al usar una prueba convencional de chi cuadrada al nivel de significación de $p=0.05$, cuando se incluyeron los términos de interacción, no hubo una diferencia significativa en la $G^{2}$. Tampoco se presentaron cambios 
significativos en los valores de $P$ en las interacciones de ningún año específico.

Por lo tanto, a pesar de los cambios sociodemográficos y de la deteriorada situación económica, la propensión total de las trabajadoras a ser asalariadas no cambió entre 1970 y 1976.

De acuerdo con lo esperado, los cambios en la composición de la población entre 1970 y 1976 tuvieron un efecto negativo sobre la probabilidad del empleo asalariado. Cuando se mantuvo constante la composición de la población en el nivel de 1970, la probabilidad del empleo asalariado fue de 0.92. Para 1976, la probabilidad del empleo asalariado disminuyó a 0.89 (véase el cuadro 12). A pesar de que el cambio fue pequeño, los hallazgos sugieren que los cambios en la composición de la población femenina afectaron al empleo asalariado.

CUADRO 12

Probabilidad pronosticada del empleo asalariado, ciudad de México, 1970-1976 ( $=1587)$

\begin{tabular}{|c|c|c|c|c|c|}
\hline Variable & $\begin{array}{c}\text { Beta de } \\
1970\end{array}$ & $\begin{array}{c}\text { Media } \\
1970\end{array}$ & $\begin{array}{c}\text { Media } \\
1976\end{array}$ & $\begin{array}{c}\text { Contri- } \\
\text { bución } \\
\text { al logito } \\
\left(70 b^{*} 70 \mathrm{~m}\right)\end{array}$ & $\begin{array}{c}\text { Contri- } \\
\text { bución } \\
\text { al logito } \\
\left(70 b^{*} 76 \mathrm{~m}\right)\end{array}$ \\
\hline Intercepción & 3.764 & 1.000 & 1.000 & 3.764 & 3.764 \\
\hline \multicolumn{6}{|l|}{ Primaria } \\
\hline incompleta & -0.692 & 0.244 & 0.261 & -0.169 & -0.181 \\
\hline Primaria completa & -0.237 & 0.629 & 0.631 & -0.149 & -0.149 \\
\hline$<35$ años & -0.780 & 0.305 & 0.324 & -0.238 & -0.253 \\
\hline Casada & -1.344 & 0.316 & 0.441 & -0.425 & -0.593 \\
\hline Separada/divorciada & -0.118 & 0.147 & 0.148 & -0.017 & -0.017 \\
\hline Viuda & -0.976 & 0.063 & 0.047 & -0.062 & -0.046 \\
\hline Migrante rural & -0.002 & 0.330 & 0.438 & -0.000 & -0.001 \\
\hline Migrante urbana & -0.023 & 0.080 & 0.207 & -0.002 & -0.005 \\
\hline 1 hijo & -0.074 & 0.117 & 0.155 & -0.009 & -0.012 \\
\hline 2 a 5 hijos & -0.673 & 0.248 & 0.332 & -0.167 & -0.223 \\
\hline 6 o más hijos & -0.936 & 0.130 & 0.132 & -0.121 & -0.123 \\
\hline Hogar extendido & -0.160 & 0.446 & 0.382 & 0.071 & 0.061 \\
\hline Otros hogares & -0.484 & 0.017 & 0.032 & -0.008 & -0.016 \\
\hline \multicolumn{6}{|l|}{ Trabajadores } \\
\hline adicionales & -0.002 & 2.646 & 2.166 & -0.007 & -0.005 \\
\hline Género del jefe & -0.367 & 0.725 & 0.714 & -0.266 & -0.262 \\
\hline Jóvenes & 0.106 & 0.450 & 0.562 & 0.048 & 0.059 \\
\hline Viejos & -0.581 & 0.183 & 0.079 & -0.106 & -0.046 \\
\hline Sirvientas & 0.918 & 0.260 & 0.187 & 0.238 & 0.172 \\
\hline Conteo del logito & & & & 2.376 & 2.125 \\
\hline \multicolumn{6}{|l|}{ Probabilidad de } \\
\hline empleo asalariado & & & & 0.915 & 0.893 \\
\hline
\end{tabular}


Al comparar a las trabajadoras con la población femenina total, encontré que la composición de las mujeres en las categorías de las variables (estatus marital de casada, condición migratoria, mujeres con 2-5 hijos, mujeres con hijos pequeños en el hogar y mujeres con sirvientas en el hogar) cambió en 5\% o más. En el cuadro 13 se considera cuál habría sido el cambio en la probabilidad pronosticada del empleo asalariado si la composición y la propensión a ser asalariadas se hubieran mantenido constantes en los niveles de 1970. Cuando sustituí por separado, las medias y los coeficientes de 1976 para cada una de las variables cuya composición cambió por más de $5 \%$ entre 1970 y 1976, la probabilidad del empleo asalariado en cada caso fue aproximadamente la misma o disminuyó ligeramente del nivel de 0.92 observado en 1970.

CUADRO 13

Cambios en la probabilidad pronosticada de empleo asalariado para variables seleccionadas, ciudad de México, 1970-1976

\begin{tabular}{lccc}
\hline Variable & $\begin{array}{c}\text { Media de } \\
1970\end{array}$ & $\begin{array}{c}\text { Media de } \\
1976\end{array}$ & $\begin{array}{c}\text { Probabilidad } \\
\text { de empleo } \\
\text { asalariado } \\
1976 B \text { 1976M }\end{array}$ \\
\hline Casada & .316 & .441 & .901 \\
Migrante rural & .330 & .438 & .915 \\
Migrante urbana & .080 & .207 & .915 \\
2 a 5 hijos & .248 & .332 & .910 \\
Hogar extendido & .446 & .820 & .914 \\
Niños pequeños & .450 & .562 & .916 \\
Sirvientas & .260 & .187 & .910 \\
\hline
\end{tabular}

Los resultados señalan que los modelos de determinación del empleo asalariado que sólo consideran los factores individuales y familiares son inadecuados para captar características esenciales del trabajo y de la demanda concomitante de trabajadoras no asalariadas en la ciudad de México. La investigación futura deberá incluir una descripción del papel de la mujer en las articulaciones entre las pequeñas unidades de empresas familiares y la producción industrial. Esta conclusión también ilustra los límites del análisis sociológico del fenómeno de la fuerza de trabajo basado exclusivamente en datos de encuestas. Muchos factores relacionados con el trabajo no asalariado son difíciles de manejar y cuantificar. En especial el trabajo de las mujeres, que está intrínsecamente vinculado a la producción y a la reproducción domésticas, determinantes que no siempre son valoradas ni mencionadas en las en- 
cuestas. El incipiente aumento del empleo no asalariado, visto ya en 1976 y observado más claramente en la década de los ochenta, debe asumirse en relación con las condiciones cambiantes de vida de las mujeres y sus hogares.

\section{Conclusiones}

La principal conclusión de esta investigación es que los cambios en los patrones del empleo femenino y en la distribución de las mujeres como trabajadoras asalariadas y no asalariadas durante los años setenta, reflejaban el efecto combinado de la privación económica creciente experimentada por los hogares y de los procesos demográficos en marcha en México. A medida que el modelo de crecimiento, basado en la sustitución de importaciones, empezó a mostrar signos de agotamiento, se revirtió el aumento secular en el empleo asalariado, al mismo tiempo que las mujeres se vieron obligadas a encontrar formas alternativas no asalariadas para obtener ingresos monetarios. Estos hallazgos son significativos porque también vaticinaban transformaciones de la fuerza de trabajo urbana en los años ochenta, que difieren únicamente en grado respecto al periodo anterior. Por último, el hecho de que algunos predictores esperados, sobre la participación femenina en la fuerza de trabajo o el empleo asalariado no fueran potentes o estadísticamente significativos, sugiere que la demanda restringida de empleo femenino en el mercado de trabajo urbano, resultante de la naturaleza del modelo de sustitución de importaciones, autolimitante e intensivo en capital, probablemente influyó en el empleo femenino más que la capacitación y las características individuales o familiares de las trabajadoras potenciales.

Los cambios en el empleo de las mujeres en la ciudad de México entre 1970 y 1976 pueden desglosarse en varios componentes. Las tendencias del empleo asalariado eran sensibles a las condiciones económicas prevalecientes y se asemejaban a las tendencias del empleo total. A pesar de ello, la estratificación de las ocupaciones por género y la división del trabajo, que mantuvo a las mujeres como dependientes económicas y como fuente de trabajo barata, permitieron la expansión de ciertos tipos de empleo femenino. Y lo que es más importante aún, la limitada demanda de trabajo impulsó a muchas mujeres a involucrarse en actividades no asalariadas. 16

16 Como consecuencia de la creciente demanda de servicios y actividades comerciales, asociada con el crecimiento físico y demográfico de los municipios alejados a pesar de la recesión, el empleo asalariado en ocupaciones tradicionalmente femeninas pudo haberse expandido en las áreas alejadas. 
La capacidad de soportar en épocas de recesión, así como en las de expansión estas tendencias del empleo femenino, se relacionó con la organización de (y la interacción entre) la familia y la economía urbana. En 1976, las transformaciones económicas y demográficas de la sociedad mexicana debilitaron la posición de las mujeres en el mercado de trabajo urbano. La oferta de trabajo femenino aumentó como resultado del tamaño de la cohorte y de la migración continua a la ciudad de México. Al mismo tiempo, la recesión condujo a una contracción de la demanda de empleo asalariado.

Para enfrentar la oferta cada vez mayor de mujeres dispuestas a trabajar y la creciente incapacidad de la economía urbana para asegurar la satisfacción de las necesidades básicas, los hogares instrumentaron una variedad de estrategias complementarias. Una de las más comunes fue el trabajo con o sin pago a las mujeres. ${ }^{17}$ Anunciando los cambios que se observarían durante la recesión de los años ochenta, los hallazgos indican que en 1976 estaba empleada una proporción significativamente más grande de mujeres casadas que en 1970. Los cambios en la participación en la fuerza de trabajo de las migrantes rurales y urbanas llaman la atención en cuanto a la necesidad de investigar más sobre los migrantes urbanos, en especial, porque a medida que la crisis se intensificaba durante los ochenta, la ciudad de México se convirtió en una ciudad de inmigración y emigración del trabajo (Cornelius, 1990). Como los migrantes urbanos han sido siempre la minoría, la investigación sociológica tendió a no prestar atención a este grupo, o se centró en las diferencias regionales en las áreas expulsoras, sin prestar la debida atención a las características de los migrantes mismos. El incentivo económico subyacente en la mayor parte de la migración a la ciudad de México, y los niveles relativamente altos de escolaridad de los migrantes urbanos sugieren que este grupo era menos vulnerable a las condiciones económicas adversas y estaba más decidido a superarlas.

17 Otras estrategias incluyeron el empleo de menores o de ancianos remunerados o no remunerados en empresas familiares, mayor número de trabajadores con ingreso por hogar, trabajadores con empleos múltiples, fondo común de ingresos, migración selectiva hacia áreas más prometedoras, y el incremento del trabajo doméstico no remunerado. Hubo hogares que se dividieron cuando algunos de sus miembros migraron a regiones en donde las perspectivas de empleo eran más promisorias o la supervivencia básica resultaba más segura. La evidencia de algunos países industrializados y de otros del Tercer Mundo sugiere que las estrategias de reproducción en términos del espacio y del tamaño de la familia, constituyen otros métodos de adaptación a las condiciones económicas (Banks, 1954; Mamdani, 1972; Caldwell, 1976). 
Aunque los cambios en la distribución de las trabajadoras entre asalariadas y no asalariadas tuvieron la dirección esperada, no fueron estadísticamente significativos. Sin embargo, los hallazgos algo expresan, ya que los modestos cambios observados fueron consistentes respecto de las tendencias posteriores. La notoria subvaloración de las actividades no asalariadas también sugiere que el empleo no asalariado puede haber aumentado más de lo que señalan los datos.

La investigación futura deberá enfatizar la amplia movilidad entre las formas de producción y el imperativo económico de mantener varias actividades simultáneamente. La transición de una forma de producción a otra está gobernada por percepciones individuales sobre la mejor forma de sobrevivir en un momento dado. Es demasiado fácil confundir el hecho real de qué es lo que hace la gente para mantener a sus familias en circunstancias difíciles, con la tentación de explicar la realidad en términos de categorías discretas, tales como asalariados versus no asalariados, o empleados versus desempleados o subempleados.

\section{Bibliografía}

Alonso, J.A. (1982), "Las trabajadoras a domicilio de la maquila del vestido en la metrópoli mexicana y sus relaciones con el capitalismo dependiente", en Estudios sobre la mujer: el empleo y la mujer. Bases teóricas, metodológicas y evidencia empírica, núm. 1, México, Secretaría de Programación y Presupuesto, Coordinación General de los Servicios Nacionales de Estadística, Geografía e Informática, pp. 459-469.

Arizpe, L. (1983), "Presentación”, en Estudios Sociológicos, vol. 1, núm. 3, México, El Colegio de México, pp. 413-415.

(1984), "Agrarian change and the dynamics of women's rural outmigration in Latin America", en UNESCO (ed.), Women on the Move: Contemporary Changes in Family and Society, Paris, UNESCO, pp. 8392.

Balán, J., H. Browning y E. Jelin (1973), Men in a Developing Society, Austin, Institute of Latin American Studies and University of Texas Press.

Banks, J.A. (1954), Prosperity and parenthood, Londres, Routledge and Kegan Paul.

Barbieri, M.T. de (1978), "Notas para el estudio del trabajo de las mujeres: el problema del trabajo doméstico", en Demografía y Economía, vol. 12, núm. 1, pp. 129-137.

Benería, L. (1979), "Reproduction, Production and the Sexual Division of Labour", en Cambridge Journal of.Economics, núm. 3, pp. 203-225. (1983), comentarios presentados en la conferencia "Women and 
Men in Contemporary Production: Capital Mobility and Labor Migration", Center for U.S.-Mexican Studies, University of California San Diego.

- y M. Roldán (1987), The Crossroads of Class and Gender: Industrial Homework, Subcontracting and Household Dynamics in Mexico City, Chicago, University of Chicago Press.

Cabrera, G. (1970), "Selectividad por edad y sexo de los migrantes en México", en Actas de la Conferencia Regional Latinoamericana de Población, México 1970, núm. 1, México, El Colegio de México, pp. 515-519.

Caldwell, John C. (1976), “Toward a Restatement of Demographic Transition Theory", en Population and Development Review, núm. 2, pp. 321-336.

Cornelius, W.A. (1975), Politics and the Migrant Poor in Mexico City, Stanford, Stanford University Press.

- (1990), Mexican Inmigrants in California Today, artículo presentado en la conferencia "California Inmigrants in World Perspective", Los Ángeles, Inmigration Research Program and International Studies and Overseas Program, UCLA (mimeo.).

Easterlin, R. (1976), "The conflict between aspirations and resources", en Population and Development Review, núm. 2, pp. 417-426.

García, Brígida (1989), "La importancia del trabajo no asalariado en la economía urbana", en Estudios Demográficos y Urbanos, vol. 4, núm. 3, México, El Colegio de México, pp. 439-465.

- y O. de Oliveira (1992), Economic Recession and Changing Determinants of Women's Work, artículo presentado en el seminario On the Demographic Consequences of Structural Adjustment in "Latin America", septiembre 29-octubre 2, Ouro Preto, Brasil, International Union for the Scientific Study of Population Ad Hoc Group on Economic Demography and Centro de Desenvolvimento e Planejamento Regional.

García, B., H. Muñoz y O. de Oliveira (1979), "Migración, familia y fuerza de trabajo en la ciudad de México", en Cuadernos del CES, núm. 26, México, Centro de Estudios Sociológicos-El Colegio de México.

- (1982), Hogares y trabajadores en la ciudad de México, México, El Colegio de México/Universidad Nacional Autónoma de México.

Hartmann, H. (1976), "Capitalism, Patriarchy and Job Segregation by Sex", en M. Blaxall y B. Reagan (eds.), Women and the Workplace: The Implications of Occupational Segregation, Chicago, University of Chicago Press, pp. 137-170.

Humphries, J. (1988) "Women's employment in restructuring America: The changing experience of women in three recessions", en J. Rubery (comp.), Women and Recession, Londres, Routledge and Kegan Paul, pp. 20-47.

Jusidman de Bialoztosky, C. (1989), "Evolución del empleo y los mercados de trabajo en México", en Memorias de la Tercera Reunión sobre la Investigación Demográfica en México, tomo 1, México, Universidad Nacional Autónoma de México/Sociedad Mexicana de Demografía, pp. 513-530. 
Lomnitz, L. (1975), "Migration and networks in Latin America", en A. Portes y H. Browning (comps.), Current Prespectives in Latin American Urban Research, Austin, Special Publication Series, Institute of Latin American Studies, University of Texas, pp. 133-150.

- (1977), Networks and Marginality: Life in a Mexican Shantytown, Nueva York, Academic Press.

Mamdani, Mahmood (1972), The Myth of Population Control, Nueva York, Monthtly Review Press.

Meillassoux, C. (1981), Maidens, Meal and Money, Cambridge, England, Cambridge University Press.

Milkman, R. (1976), “Women's work and economic crisis: Some lessons of the Great Depression", en Review of Radical Political Economics, vol. 8, núm. 1, pp. 73-97.

Oliveira, O. de (1989), "Empleo femenino en México en tiempos de expansión y recesión económica: tendencias recientes", en Fuerza de trabajo femenina urbana en México: características y tendencias, núm. 1, México, Coordinación de Humanidades-unam/Miguel Ángel Porrúa, pp. 29-66.

Peattie, L.R. (1987), "An Idea in Good Currency and How it grew: The Informal Sector", en World Development, vol. 15, núm. 7, pp. 851-860.

Portes, Alejandro y Laura Benton (1984), "Industrial Development and Labor Absorption", en Population and Development Review, núm. 10, pp. 589-612.

y J. Walton (1981), Labor, Class and the International System, Nueva York, Academic Press.

Rendón, T. y C. Salas (1987), "Evolución del empleo en México, 18951980", en Estudios Demográficos y Urbanos, vol. 2, núm. 2, pp. 189231.

Rubery, J. (comp.) (1988), Women and Recession, Londres, Routledge and Kegan Paul.

Rubin-Kurtzman, Jane R. (1991a), "Los determinantes de la oferta de trabajo femenino en la ciudad de México, 1970", en Estudios Demográficos y Urbanos, vol. 6, núm. 3, pp. 545-582.

(1991b), "From Prosperity to Adversity: The Labor Force Participation of Women in Mexico City, 1970-1976", tesis de doctorado en sociología, Los Ángeles, Universidad de California.

_ـ (1993), "Heterogeneidad ocupacional y empleo femenino en la ciudad de México, 1970", en Estudios Demográficos y Urbanos, vol. 8, núm. 1 (22), pp. 121-156.

Souza, Paulo Renato y Victor Tokman (1975), El sector informal urbano, Santiago de Chile, Consejo Latinoamericano de Ciencias Sociales, Grupo sobre Trabajo y Desocupación.

Tello, C. (1986), La política económica en México: 1970-1976, 8a. edición, México, Siglo XXI Editores. 
